\title{
STUDI POSKOLONIAL TERHADAP KAWASAN ALUN-ALUN JEMBER: USAHA MENGGALI POTENSI KOTA KREATIF
}

\author{
Y.A. Widriyakara S., Anas Hidayat, Lucia Ina Trisjanti \\ Program Studi Arsitektur, Fakultas Teknik, Universitas Katolik Darma Cendika, \\ Jl. Dr. Ir. H. Soekarno 201, Surabaya \\ Email: widri_ukdc@yahoo.com, anashiday@yahoo.co.uk,67padma@gmail.com
}

\begin{abstract}
Abstrak
Alun-alun merupakan kawasan penting dalam kota di Jawa yang sudah ada sejak masa prakolonial (bisa dirunut sejak Majapahit), kemudian diadaptasi secara kreatif pada masa kolonial Belanda hingga masa pasca kemerdekaan Indonesia. Kajian tentang Alun-alun kebanyakan dilakukan secara historis, simbolis atau fungsional, sedangkan kajian ini melihat dari sudut pandang poskolonial yang membalik sudut pandang: dari Alun-alun yang dianggap pasif dan dipengaruhi, menjadi Alun-alun yang aktif dan bisa sejajar dengan arus global. Metode penelitian yang dipakai adalah metode penelitian kualitatif, dengan melihat kreativitas masyarakat Jember dalam proses perubahan yang terjadi. Kajian ini menggabungkan antara pengamatan langsung, jelajah dokumen dan wawancara. Alun-alun menjadi sebuah jejak media "penguasaan" yang dilakukan oleh kolonial Belanda (terhadap Indonesia/Jember) hingga era Orde Baru (terhadap rakyat Indonesia/Jember), masyarakat dianggap liyan (others). Kemudian mencari bentuk baru dengan meniru dan membalik dari apa yang sudah dilakukan oleh para "penguasa" tersebut sehingga menjadi alun-alun yang hibrid, diaspora, dan terjadi transkulturasi juga. Kawasan alunalun Jember dari pandangan poskolonial memiliki sifat dinamis dan adaptif. Masyarakat dan alunalun Jember bukan entitas pasif yang marjinal dan hanya menerima pengaruh dari luar, tetapi subjek yang kreatif dalam perubahan, agar bisa sejajar dengan entitas yang lebih maju.
\end{abstract}

Kata kunci: alun-alun, poskolonial, subjek, kota aktif, kota kreatif

\begin{abstract}
Title: Postcolonial Study towards Jember Alun-alun Area: Efforts to Explore the Potential of Creative City
\end{abstract}

The Alun-alun is an important area in the city in Java, which has existed since pre-colonial era (can be traced back to the Majapahit era), which was later adapted creatively by the Dutch in colonial era to the post-independence of Indonesia. Studies on the Alun-alun is mostly done historically, symbolic or functional, whereas this study viewed from the perspective of postcolonial, that reverse point of view: from the square is considered passive and influenced, being square is active and can be aligned with the global trend. The research method is qualitative research, with a view creativity of Jember society in the process of changes. This study combines direct observation, observe documents and interview. Alun-alun became a media of "control" by the Dutch (towards Indonesian/Jember society) to the New Order era (towards the people of Indonesia/Jember), society is assumed to be liyan (others). Then look for new forms to imitate and reverse of what has been done by the "authorities" so that an alun-alun will be hybrid, diaspora and transculturation also occur. Jember alun-alun area from postcolonial view has a dynamic and adaptive character. Community and Jember alun-alun are not a passive entity that is marginalized and only accept influence from the outside, but they are the subject of the creative changes, to be aligned with a more advanced entity.

Keywords: alun-alun/square, postcolonial, subject, active city, creative city 


\section{Pendahuluan}

Kota Jember merupakan sebuah kota di Jawa Timur bagian timur yang pada awalnya dibentuk oleh pemerintah Belanda di jaman kolonial, dan dalam perkembangannya akhirnya menjadi ibukota dari kabupaten Jember sampai sekarang ini. Kota ini berkembang dari nol, dan berkembang karena banyak pendatang yang ingin mengubah kehidupan (Adisasmita, 2010), dibentuk oleh proses migrasi (Hariyono, 2007). Jember adalah salah satu kota yang cukup penting di Jawa Timur baik secara budaya, ekonomi dan politik, antara lain terbukti dari adanya perguruan tinggi negeri (Universitas Jember), juga adanya bandar udara (bandara) yang menghubungkan Jember dengan Surabaya, bahkan Jember juga punya agenda kreatif yang sudah menjadi agenda Internasional, yaitu JFC (Jember Fashion Carnival). Selain itu, Jember juga menjadi daerah dalam fase peralihan yang dinamis, yang berada antara desa dan kota (Pontoh dan Kustiwan, 2009)

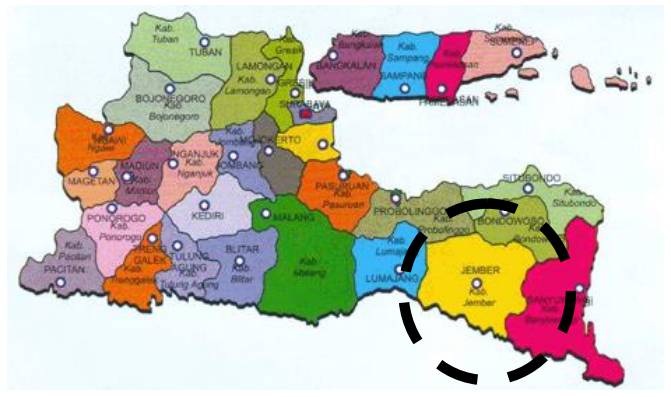

Gambar 1. Peta Jawa Timur

Sumber:https://duniacaktuh.files.wordpress.com /2012/11/jatim.gift

Jadi, jika dibandingkan dengan kotakota lain di Jawa Timur seperti Kediri, Ponorogo, Blitar, Probolinggo, Surabaya ataupun Banyuwangi, maka Jember bisa dikatakan jauh lebih muda. Justru ini menjadi menarik karena kota ini bisa dirunut akar genesisnya secara lebih jelas dan jernih. Perkembangannya pun lebih mudah untuk dipelajari dan dipetakan, bahkan juga bisa untuk dikaitkan dengan isu-isu kontemporer dan wacana yang sedang booming saat ini, antara lain wacana poskolonial (pascakolonial).

Bibit dan jejak kreativitas kota dan masyarakat Jember pun bisa dirunut dari Alun-alunnya, yang memiliki sejarah dan perubahan yang khas dan kreatif. Ini menjadi sebuah pijakan untuk menentukan strategi kota. Bahwa kota yang unggul diawali dari konsep dan strategi yang unggul juga (Laksono, 2013)

\section{Perkembangan Historis}

Kota Jember pada mulanya adalah sebuah kota kecil yang sepi dan terisolir. Dengan kehadiran sistem perkebunan swasta Belanda yang membawa perubahan-perubahan sosial dan ekonomi di masyarakat serta perubahan status kota Jember pada tahun 1883. Status kota Jember pada waktu itu menjadi salah satu bagian distrik dari regentschap (kabupaten) Bondowoso di wilayah karesidenan Besuki, yang kemudian berkembang menjadi regentschap terpisah dari Bondowoso. Pertumbuhan kota Jember dapat dikatakan sangat pesat terutama di pertengahan abad ke 19 sampai awal abad ke 20, dibandingkan dengan kabupaten-kabupaten yang ada di Besuki, seperti Kabupaten Panarukan, Kabupaten Bondowoso, dan Kabupaten Banyuwangi.

Pertumbuhan kota Jember menjadi lebih pesat dibandingkan dengan kabupaten-kabupaten yang lainnya, oleh karena sistem kapitalisme memberi peluang bagi pembukaan perkebunan-perkebunan swasta/pribadi yang menjamur pada masa itu. Melalui kebijakan ekonomi yang disebut 
dengan the system of enterprise. Sistem baru dari pemerintah Hindia-Belanda ini memberikan dukungan dan fasilitas kepada pihak swasta dengan tujuan agar hasil tanaman komoditi ekspor dapat memberikan keuntungan atau devisa bagi pemerintah HindiaBelanda.

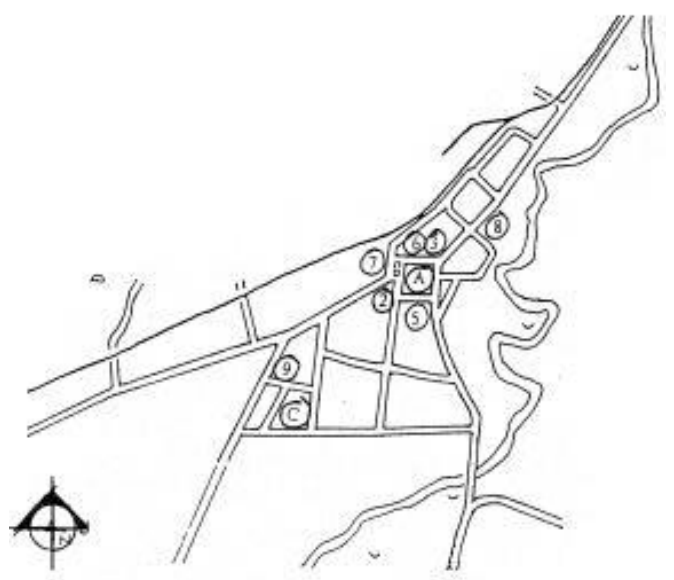

Gambar 2. Alun-alun Jember di masa Kolonial Belanda

Sumber: Handinoto, 2010

Dari catatan sejarah dan dari dokumendokumen berdirinya N.V. LMOD (Landbauw Maatshcappij Oud Djember) yang merupakan perusahaan besar jaman itu, dapat dijadikan dasar yang akurat tentang asal usul kota Jember dibandingkan versi-versi yang lainnya. Kemudian, berdasarkan Staatsbland Nomor 322 pada tanggal 9 Agustus 1928 ditetapkanlah Kabupaten Jember yang berlaku tanggal 1 Januari 1929 dibentuk dan sebagai dasar hukum mulai berlaku. Pemerintah Hindia-Belanda telah mengeluarkan ketentuan tentang penataan kembali pemerintah desentralisasi di wilayah Provinsi Jawa Timur, antara lain dengan menunjuk Regentschap Djember sebagai masyarakat kesatuan hukum yang berdiri sendiri. Secara resmi ketentuan tersebut diterbitkan oleh Sekretaris Umum Pemerintah Hindia Belanda (De Aglemeene
Secretaris) G.R. Erdbrink, 21 Agustus 1928. Pemerintah Regentschap Jember yang semula terbagi dalam tujuh Wilayah Distrik, pada tanggal 1 Januari 1929 sejak berlakunya Staatsbland No. 46/1941 tanggal 1 Maret 1941.

Kemudian, berdasarkan pada Undang Undang No. 12/1950 tentang Pemerintah Daerah Kabupaten di Jawa Timur, ditetapkan pembentukan Daerah-daerah Kabupaten dalam lingkungan Propinsi Jawa Timur (dengan Perda), antara lain Daerah Kabupaten Jember ditetapkan menjadi Kabupaten Jember. Dengan dasar Peraturan Pemerintah Nomor 14 Tahun 1976 tanggal 19 April 1976, dibentuklah Wilayah Kota Jember dengan penataan wilayah-wilayah baru.

\section{Keberadaan Alun-alun}

Seperti halnya kota-kota lain di Jawa, Jember juga memiliki sebuah Alunalun kota yang punya ciri khas dan karakteristik tersendiri, sekaligus juga sebagai identitas kota Jember. Sebagai sebuah landmark kota, Alun-alun Jember juga menjadi representasi dari proses penguasaan dan penaklukan, pertentangan budaya, perbedaan paham dan kelas, juga jejak dan bibit kota kreatif yang terjadi sejak masa penjajahan Belanda hingga saat ini.

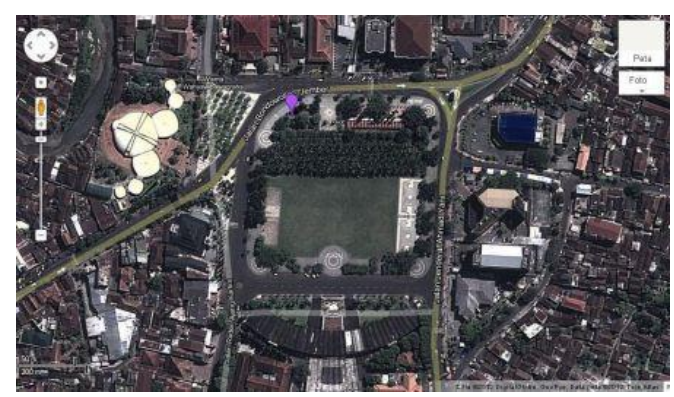

Gambar 3. Kawasan Alun-alun Jember di masa Sekarang

Sumber: Google earth, 2015 
Sebagai Alun-alun yang muncul pada masa kolonial (bukan sejak jaman kerajaan-kerajaan di Jawa), dan dirancang pada mulanya oleh pemerintah kolonial, maka Alun-alun ini menjadi cukup unik. Pemerintah kolonial pun di masa itu masih mengadopsi budaya ruang publik setempat, yaitu alun-alun Jawa, sehingga masyarakat menjadi tidak asing dengan keberadaan alun-alun ini dan bisa diterima secara spasial dan bukan sebagai elemen "asing" yang ditambahkan begitu saja dalam kehidupan keseharian mereka.

\section{Dari Masa Kolonial ke Masa Kini}

Proses-proses dari representasi tersebut lebih sering dilihat dari kacamata kolonial (modern), di mana pihak yang dominan/berkuasa menjadi subjek yang aktif dan punya power, mendominasi dan berada di pusat (sentral) yang menentukan kebijakan penataan ruang dan perancangan kawasan kota, sedangkan rakyat kebanyakan menjadi pihak yang resesif (powerless) menjadi objek yang pasif, didominasi dan berada di pinggiran (marjinal) (Kusno, 2006).

Dalam kajian poskolonial ini, justru pihak yang terpinggirkan dijadikan sebagai subjek yang aktif dan kreatif, yang punya andil dalam perkembangan Alun-alun Jember dari masa ke masa. Jadi, kota yang tak hanya berdasar pada utopia atau impian satu pihak, tetapi banyak impian/heterotopia dari banyak pihak yang terlibat di dalamnya (Dehaene \& De Cautier, 2008)

\section{Metode}

Metode yang dipakai dalam penelitian ini adalah metode penelitian kualitatif, dengan melakukan pembandingan antara alun-alun dari sudut pandang kolonial dan alun-alun dari sudut pandang poskolonial, di mana yang bersifat poskolonial lebih diutamakan sebagai sudut tinjaunya. Dengan metode kualitatif yang merupakan metode yang menghasilkan data tertulis dari objek yang diamati (Moleong, 2004), bukan data terukur yang positivistik (Surakhmad, 1994 dan Purnomo, 2009). Dengan demikian, akan lebih mudah untuk meyesuaikan dengan kenyataan yang kompleks di Alun-alun Jember, bisa langsung berhubungan dengan para pengguna Alun-alun dan lebih peka untuk melakukan penajaman-penajaman dalam kajian.

Untuk mendukung metode tersebut, juga dilakukan pengamatan langsung secara visual untuk menggali unsurunsur yang bersifat poskolonial dan bagaimana pemanfaatannya untuk pengembangan Alun-alun di masa mendatang. Metode penelitian kualitatif ini dilakukan dengan proses yang terstruktur untuk menggali dan menganalisa objek. Proses itu meliputi: menentukan subjek dan objek penelitian, studi dokumen, studi lapangan, wawancara dan observasi, serta analisa secara lebih mendetail dan tajam.

\section{Subjek dan Objek penelitian}

Dalam penulisan ilmiah ini, yang menjadi subjek penelitian adalah isuisu poskolonial yang disesuaikan dengan konteks kota Jember dan alunalunnya. Isu-isu ini diambil dari poinpoin penting wacana poskolonial yang kemudian diterapkan sebagai sudut pandang dalam melihat dan mengamati Alun-alun. Di sini isu-isu poskolonial menjadi alat untuk membedah dan menganalisa, bagaimana Alun-alun Jember ini berkembang dan bagaimana isu-isu itu bisa bekerja secara efektif di dalamnya. 
Sedangkan yang menjadi objek penelitian ialah Alun-alun Jember. Objek di sini adalah pihak yang diamati dan dianalisa. Tetapi, alun-alun Jember dan bangunan pelingkupnya ini bukanlah objek yang pasif, melainkan objek aktif yang bisa saja memberikan koreksi dan revisi terhadap prinsip dan isu poskolonial, dengan tetap berdasar pada order dan struktur (Crowe, 1997) yang "tetap". Dalam kasus kota Jember ini, koreksi dari objek sangat mungkin terjadi, karena teori poskolonial merupakan isu yang bersifat ideal da teoretis, sedangkan Alun-alun ini berupa objek nyata yang sudah terbangun, yang sangat potensial memunculkan teori baru juga berkaitan dengan studi-studi poskolonial.

\section{Observasi Skala Kota}

Observasi skala kota ini untuk meneropong kawasan yang lebih luas (bukan hanya sekitar alun-alun saja) sebagai sebuah sekuen atau perjalanan ruang (Ching, 2012), untuk melihat dampak dan korelasi terhadap lingkungan dan kota Jember secara keseluruhan. Sebab Alun-alun merupakan sebuah entitas yang tidak berdiri sendiri, tetapi selalu berkaitan dengan kota secara holistik, selalu menjadi bagian yang penting dari sebuah kota.

Kajian senada sudah dilakukan pada kota lain seperti Medan dan Purworejo dengan paradigma kajian yang berbeda, misalnya berdasar pada kualitas ruang publik (Prihastoto 2003 dan Fyfe, 1998), dan juga memori kolektif (Utami, Ginting dan Eddy, 2004)

Jadi, hasil yang didapat pada studi lapangan dan wawancara dibawa ke dalam konteks yang lebih luas pada skala kota/urban, sehingga didapatkan gambaran tentang Alun-alun Jember yang lebih lengkap dan komprehensif, bagaimana pengaruh kreatifnya pada kota Jember secara umum, bahkan juga termasuk dampaknya terhadap wilayah Kabupaten Jember.

\section{Konsep Analisis}

Analisis terhadap alun-alun Jember dilakukan dengan menggunakan 2 (dua) prinsip Poskolonial, yaitu: diaspora (menyebar) dan hybridity (persilangan), pada alun-alun Jember. Dengan alasan dua prinsip ini merupakan prinsip yang cukup populer dalam kajian poskolonial.

Jadi, data yang didapat di atas kemudian dianalisis dari prinsip poskolonial, untuk dibandingkan dengan teori yang ada, sehingga ditemukan kesesuaian atau ketidaksesuaian. Ketidaksesuaian ini justru menjadi embrio munculnya teori baru poskolonial untuk Alun-alun Jember.

\section{Pembahasan dan Hasil}

Sebagai wacana yang muncul di masa setelah modern yang bersifat plural (beragam, dan menyadari keragaman subjek), maka poskolonial menjadi isu penting yang bisa dipakai untuk menganalisis berbagai macam fenomena di segala bidang, mulai dari kota, masyarakat, antropologi dan sosiologi, psikologi, ekonomi, sastra, seni, budaya dan lain sebagainya.

Isu-isu di dalam kajian poskolonial jumlahnya sangat banyak, yang saat ini berkembang dan makin banyak digunakan oleh kalangan akademik. Penggunaan dari isu-isu tersebut tentunya disesuaikan dengan konteks penelitiannya. seperti: discourse (wacana), ambivalence (mendua), authenticity (otentisitas), contrapuntal reading (pembacaan kontrapuntal), diaspora (menyebar), dislocation 
(dislokasi), hegemony (hegemoni), hybrid (hibrid), native (asli), dan lain sebagainya.

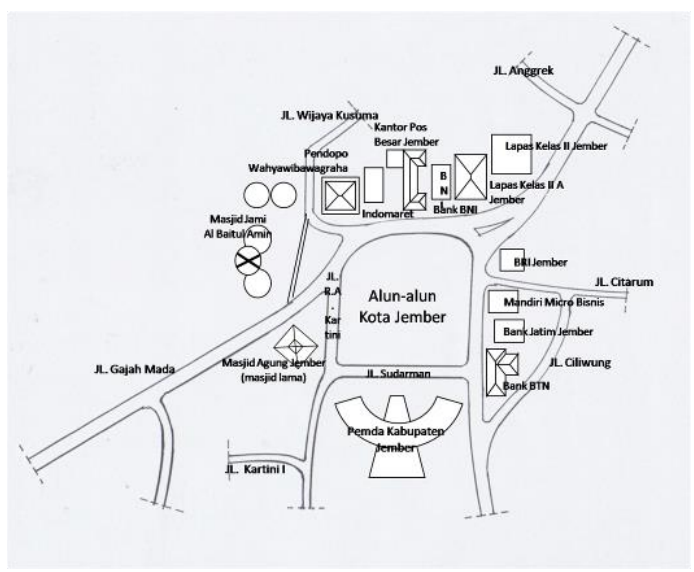

Gambar 4. Peta Kawasan Alun-alun kota Jember dan Bangunan Sekitarnya.

Sumber: Dokumentasi penelitian, 2016

Juga di dalam arsitektur, isu poskolonial menjadi wacana yang ramai diperbincangkan secara ilmiah sejak tahun 1990-an. Dan isu ini mampu memetakan keadaan dan kondisi arsitektur di negara-negara dunia ketiga yang sebelumnya pernah dijajah oleh bangsa Barat selama ratusan tahun.

\section{Diaspora (Menyebar)}

Diaspora atau menyebar merupakan sebuah konsep poskolonial yang berkaitan dengan isu sentral (pusat) dan marjinal (pinggiran), di mana kemudian terjadi sebuah persebaran yang sudah tak mempermasalahkan mana yang asli atau tidak, mana yang lebih tinggi atau lebih rendah, semua memiliki derajat sama.

Diaspora berasal dari bahasa Yunani yang artinya menyebar (to disperse). Diaspora merupakan sebuah pergerakan mausia dari satu tempat ke tempat yang lain (Ashcroft, Griffiths, and Tiffin 1998). Dalam konsep diaspora ini, diawali ketika orang Eropa menyebar ke seluruh dunia, sehingga mempengaruhi budaya di tempat-tempat yang mereka duduki (jajah).

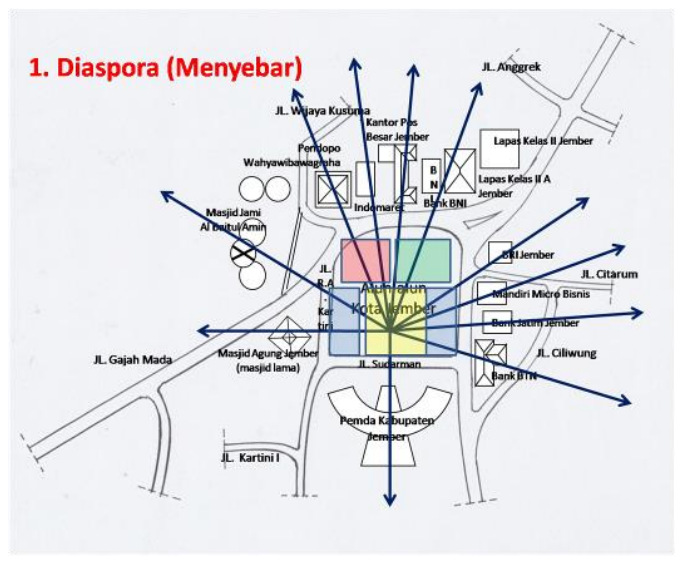

Gambar 5. Peta Diaspora Kawasan Alunalun kota Jember

Sumber: Dokumentasi penelitian, 2016

Unsur diaspora yang terlihat di Alunalun Jember ini menunjukkan Alunalun Jember yang tanpa pusat, cenderung menyebar (lihat Gambar 5). Jika dulunya kekuasaan terpusat di tangan pemerintahan (kolonial) dengan bangunan di sisi selatan dan kekuasaan spiritul-religius di sisi barat (Masjid), maka saat ini terlihat ada banyak kekuasaan yang berbeda yang masuk di dalam dan sekitar alun-alun. Misalnya kekuatan/kekuasaan kapital (modal) ataupun kekuatan demokratis (dari rakyat, oleh rakyat, untuk rakyat). Ini merupakan kekuatan kreatif kota untuk menyebar ke segala arah.

Pada alun-alun Jember masa lalu (di masa kolonial), sangat terlihat bahwa empat arah mata angin alun-alun Jember ditempati oleh empat bangunan utama sebagai kiblat papat limo pancer (empat arah mata angin, dan yang kelima adalah pusatnya) (Frick, 1997). Di bagian selatan adalah kantor asisten residen di Jember, di bagian barat ada masjid (masjid lama), di bagian utara ada penjara, dan di bagian timur ada pasar. 
Selain itu, Belanda juga membuat segregasi wilayah dengan batas alunalun Jember ini. Bagian alun-alun ke arah utara sebagai kawasan eksklusif untuk warga Belanda, sedangkan bagian alun-alun ke arah selatan adalah kawasan untuk warga pribumi.

\section{Selatan}

Saat ini, bagian selatan adalah bagian yang paling konsisten dengan satu fungsi, yaitu sebagai kantor pusat Pemerintah Kabupaten Jember beserta kantor-kantor penunjangnya.

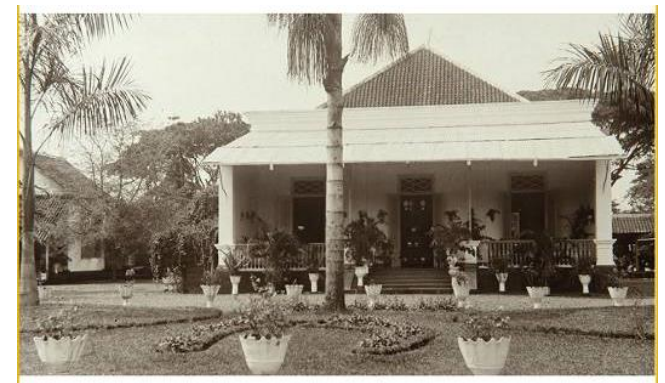

Gambar 6. Kantor Regentschap (Kantor Asisten Residen) Jember pada masa Kolonial Belanda.

Sumber:http://majalahtelapak.blogspot.com/ 2013/01/dinamika-pemerintahan-dikabupaten.html

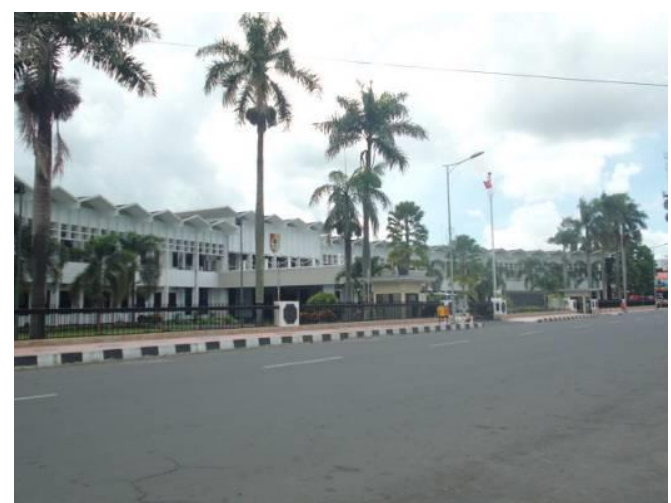

Gambar 7. Kantor Pemkab Jember di masa sekarang.

Sumber: Dokumentasi penelitian, 2016

Itupun sudah bukan satu massa bangunan saja seperti pada masa kolonial dulu, tetapi ada banyak massa yang berada di belakang (di sebelah selatan) bangunan utama. Penambahan massa-massa ini karena kebutuhan ruang kantor Pemerintah Kabupaten Jember yang semakin bertambah kompleks juga.

\section{Barat}

Di sisi barat alun-alun juga terjadi diaspora, yakni terpecah menjadi dua sumbu religius, yaitu bangunan masjid. Sumbu yang pertama adalah masjid lama (berbentuk tajug) yang dibagun sejak tahun 1883, yang sudah diubah fungsinya menjadi sebuah yayasan sekolah Islam.

Sedangkan sumbu yang kedua adalah masjid baru berupa masjid modern yang dibangun sejak tahun 1978, dengan atap shell besar yang menjadi ikon baru di sebelah barat alun-alun Jember sampai sekarang ini.

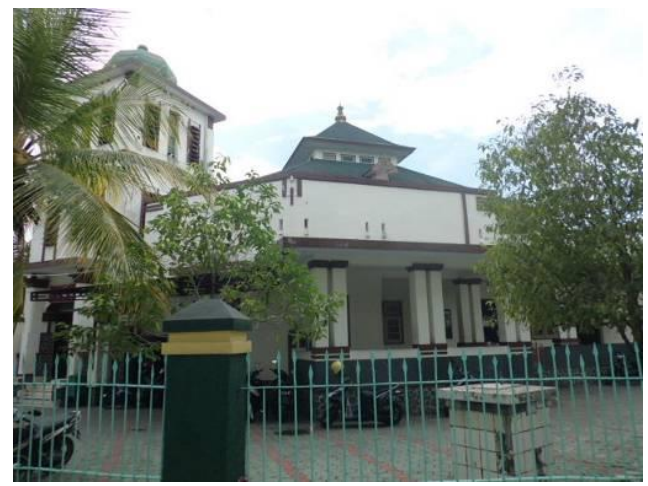

Gambar 8. Masjid Lama tajug di sebelah barat Alun-alun Jember.

Sumber: Dokumentasi penelitian, 2016

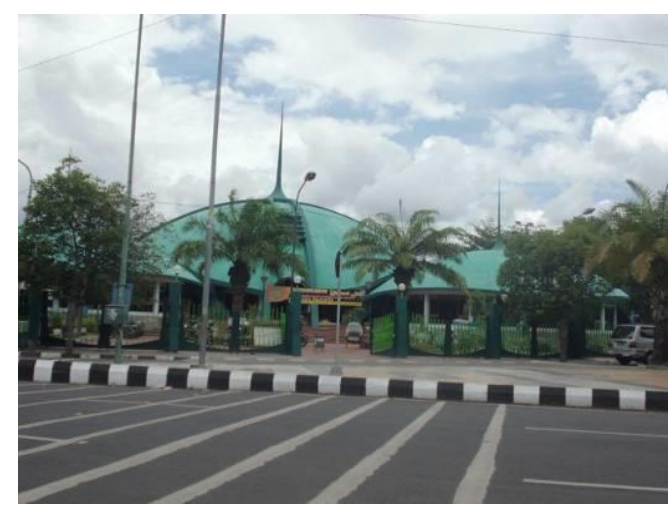

Gambar 9. Masjid Baru berbentuk shell di sebelah barat Alun-alun Jember.

Sumber: Dokumentasi penelitian, 2016 
$\underline{\text { Utara }}$

Bagian sisi utara merupakan sisi yang paling dinamis disporanya saat ini. Di sini tidak ada bangunan yang dominan, dan lebih terlihat sebagai kumpulan massa-massa bangunan yang berderet dan berasal dari masa (waktu) pembangunan yang berbeda-beda tetapi tidak berurutan, membentuk sebuah perjalanan historis yang acak (random).

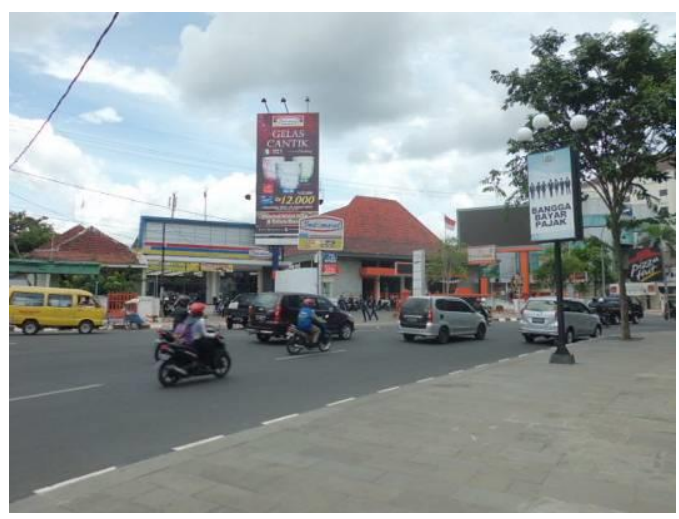

Gambar 10. Sisi Utara Alun-alun dengan berbagai macam bangunan, baik bentuk maupun fungsinya.

Sumber: Dokumentasi penelitian, 2016

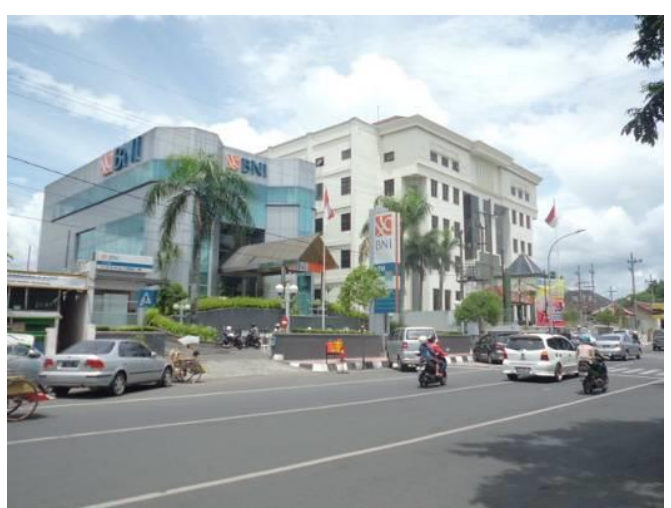

Gambar 11. Sisi Timur Alun-alun Jember dengan gedung-gedung Bank yang berupa hi-rise building (bertingkat tinggi)

Sumber: Dokumentasi penelitian, 2016

\section{Timur}

Sedangkan sisi timur juga merupakan deretan bangunan yang bermacammacam modelnya, tetapi yang paling dominan di sini adalah kantor-kantor bank. Rata-rata sudah merupakan bangunan tinggi (untuk ukuran kota
Jember), menjadi sisi yang bangunanbangunannya paling jangkung (tinggi) jika dibandingkan sisi-sisi yang lainnya.

\section{Hybridity (Persilangan)}

Hibrid atau hybrid merupakan kondisi persilangan. Dalam kondisi hibrid, keaslian atau keotentikan menjadi hal yang tidak relevan lagi, karena semua hal pada dasarnya adalah persilangan antara hal yang satu dengan yang lainnya, antara yang asli (original) dengan yang tidak asli, antara yang awal dan yang turunan.

Hybrid merupakan istilah yag dimunculkan oleh Homi Bhaba, seorang tokoh poskolonial, untuk menyebut gejala yang terjadi antara si penjajah (colonizer) dan si terjajah (colonized). Keduanya berada dalam kondisi in-between (di antara), dan akhirnya memunculkan budaya hibrid, yang mencampurakan dua unsur budaya yang berbeda (Ashcroft, Griffiths, and Tiffin 1998).

$\mathrm{Si}$ penjajah berusaha mengambil sesuatu dari yang terjajah sebagai sesuatu yang "baru" (mungkin juga eksotik), sedangkan yang terjajah ingin meniru si penjajah agar dianggap sejajar/setara dan lebih maju.

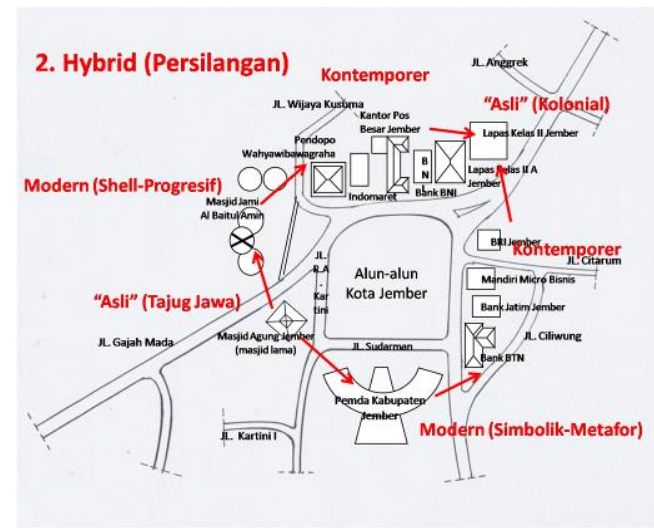

Gambar 12. Peta Hibriditas Kawasan Alunalun kota Jember

Sumber: Dokumentasi penelitian, 2016 
Hibrid merupakan persilangan. Kota Jember sendiri yang juga sebagai sebuah persilangan, sangat mendukung keberadaan alun-alun yang berkarakter persilangan juga. Di Alun-alun Jember ini, antara lain terlihat persilangan antara yang tradisional (Masjid Tajug) dengan yang modern (Masjid Bundar/Shell), antara yang komersial (Bank, Toko) dengan yang formalbirokratis (Kantor Pemkab Jember), juga antara fungsi religius (Masjid) dan fungsi rekreatif (lapangan tengah alunalun yang menjadi sarana olahraga dan juga playground.

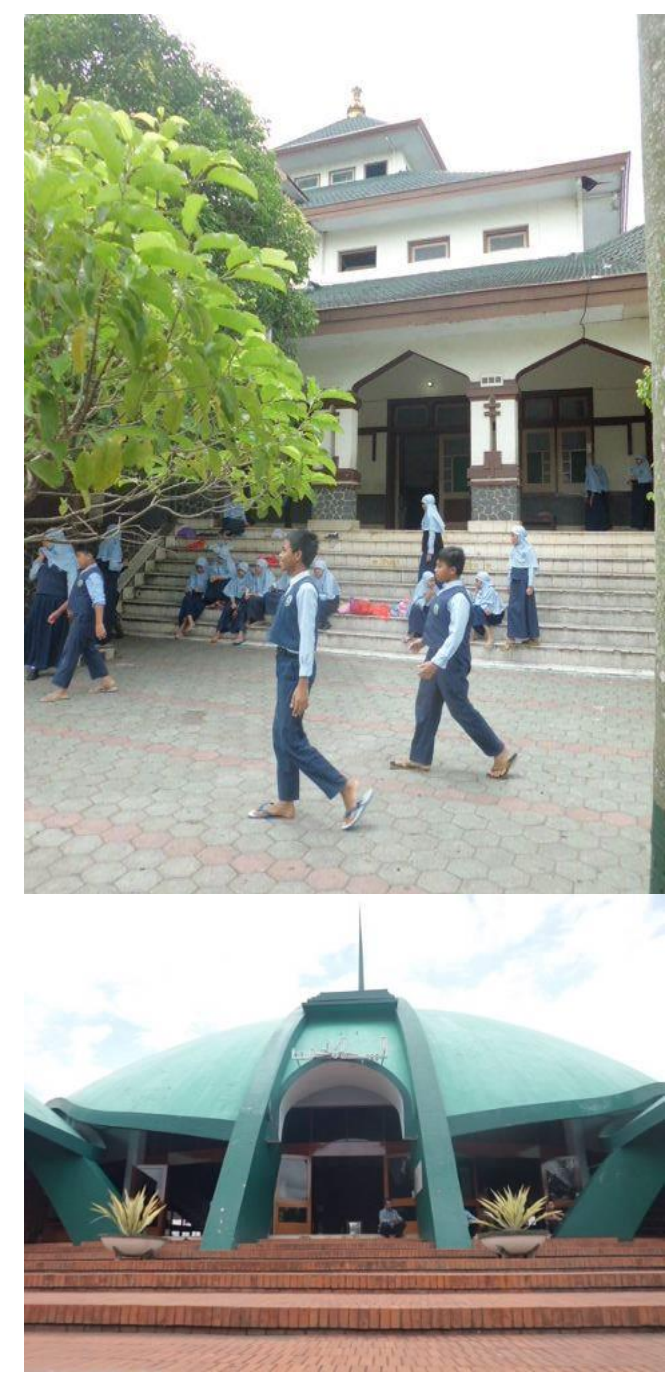

Gambar 13a dan 13b. Hybrid antara masjid tajug dan mesjid shell di sisi barat Alun-alun Jember.

Sumber: Dokumentasi penelitian, 2016
Masjid kuno-kini

Masjid di sebelah barat Alun-alun Jember menunjukkan hibriditas, tetapi bukan hibriditas yang terjadi dalam satu bangunan, melainkan dalam dua bangunan yang berbeda.

Masjid lama yang beratap tajug dan masjid baru yang beratap kubah shell menunjukkan sebuah percampuran antara tradisi dan modernitas yang ternyata bisa hadir bebarengan (bersamaan) dalam sebuah lokasi yang berdekatan. Keduanya adalah tetap masjid, dengan pandangan kultur yang berbeda, yang berdasar tradisi dan yang modern.

\section{Bangunan komersial-birokratis}

Hibriditas yang paling mencolok dan sangat jelas terlihat berada di sisi utara, di mana ada percampuran antara fungsi bangunan yang komersial dan yang birokratis, antara yang lama (kolonial dan juga joglo), serta bangunanbangunan masa kini yang lebih bersifat kontemporer.

Selain itu, juga percampuran antara yang historis (menyejarah) dan yang ahistoris (tidak menyejarah). Semua bisa hadir sebagai bagian dari pemunculan hibriditas yang cukup kompleks dan menunjukkan proses perkembangan alun-alun yang semakin berkembang pesat. Ada yang dari masa kolonial, ada yang dari masa tahun 1970-an, 1980-an, 1990-an hingga ke masa sekarang ini.

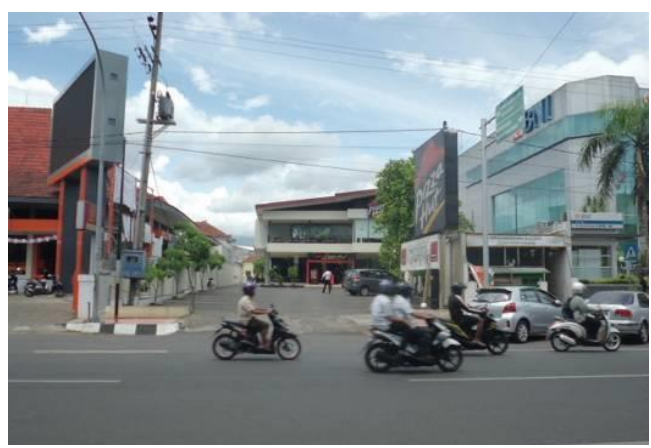




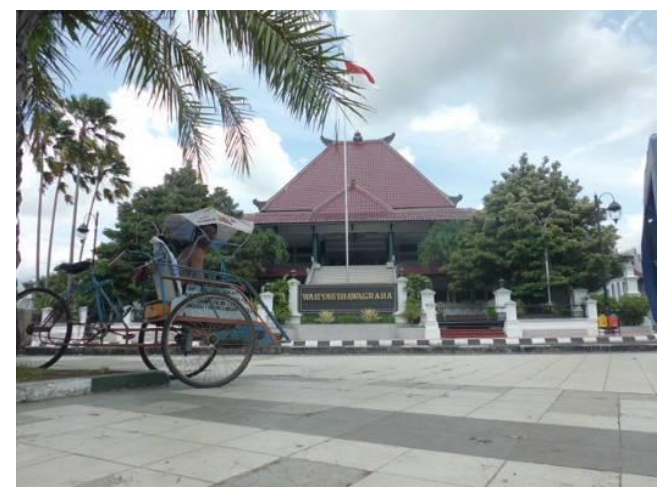

Gambar 14a dan 14b. Hybrid antara bangunan komersial dan bangunan birokratis di sisi utara Alun-alun Jember Sumber: Dokumentasi penelitian, 2016

Ruang kosong-fungsional

Alun-alun yang berada di tengah kawasan ini, dahulu merupakan ruang kosong (berupa hamparan rumput dengan beberapa pepohonan), yang hanya sesekali saja dipakai bila ada acara publik seperti pesta rakyat, atau untuk upacara.

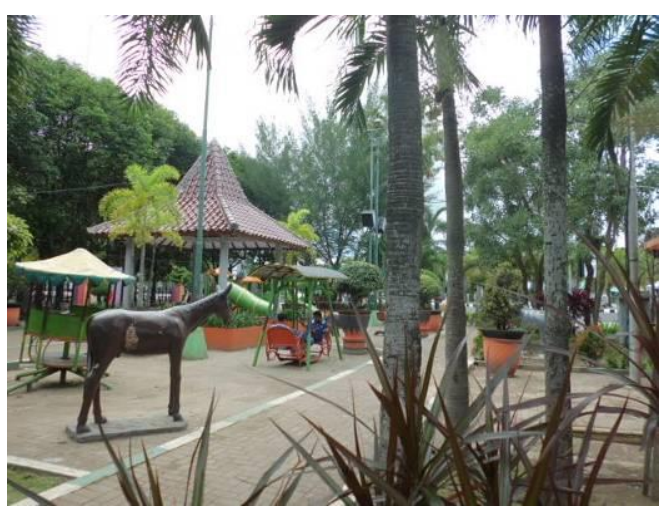

Gambar 15. Playground, sebagai fungsi baru yang masuk ke dalam Alun-alun Jember.

Sumber: Dokumentasi Penelitian, 2016

Sekarang di alun-alun Jember sudah terjadi hibrid (percampuran) antara ruang kosong dengan ruang-ruang yang lebih fungsional. Misalnya saja, di bagian dalam alun-alun ini ada fungsi sebagai sentra kuliner (memasukkan pedagang kaki lima), ada playground yang dikhususkan untuk anak-anak dan juga lapangan olahraga (voli dan basket) sebagai pelengkap fasilitas bagi warga kota di masa sekarang.

\section{Kesimpulan}

Kesimpulan yang bisa ditarik dari rangkaian penelitian ini adalah, bahwa Alun-alun yang berada di pusat kota Jember ini ternyata menjadi kasus yang cukup layak bagi isu-isu poskolonial, terutama prinsip diaspora dan hibrid/hybrid, sekaligus memberikan koreksinya sebagai timbal-balik. Jadi, bukan sebagai objek yang pasif, tetapi juga objek aktif dan kreatif.

Alun-alun Jember juga memberi koreksi, antara lain bahwa isu poskolonial pun juga masih perlu dicross-check dengan realitas. Contohnya dua masjid yang tetap berdiri, menujukkan bagaimana jejak masjid di Alun-alun Jember merupakan jejak yang utuh. Dengan jejak yang utuh itu, maka karakter masjidnya bukan sebuah campuran dalam satu bangunan, melainkan ada dua gedung masjid yang berdampingan. kondisi ini sangat khas dan sangat jarang dijumpai di kota lain (di luar Jember).

Selain itu, alun-alun Jember menjadi jejak dan media kreatif yang menunjukkan bagaimana masyarakat Jember berani dan kontekstual dalam membuat gebrakan yang signifikan dalam mengolah tatanan dan bangunan di alun-alun dan sekaligus penataan ruang yang ada di dalamnya, dengan tetap mempertahankan guna dan citranya (Mangunwijaya, 2013), serta ada proses transkulturasi sebagai proses yang bersifat lintas budaya (Hernandez, Millington and Borden, 2005).

\section{Saran}

Penelitian ini masih memungkinkan untuk ditinjau dari sudut pandang yang lain yang berbeda, sehingga bisa 
memperkaya wacana untuk meneliti Alun-alun Jember. Juga masih memungkinkan juga untuk menganalisa alun-alun di kota-kota lain dari isu poskolonial. Jadi subjek dan objek penelitian ini masih bisa dikembangkan lagi.

Penelitian ini juga bisa dijadikan titik awal sebagai upaya untuk memperkaya wacana antara subjek dan objek, menjadi permulaan dari pengembangan berikutnya dan sekaligus menjadi pemerkaya teoretis dari wacana yang bersifat poskolonial agar lebih dikenal secara lebih luas sebagai salah satu wacana kajian.

\section{Ucapan Terima Kasih}

Ucapan terimakasih yang setinggitingginya kami haturkan kepada segenap civitas akademika di Universitas Katolik Darma Cendika yang telah dan selalu mendukung kami dalam membuat kajian penelitian ini. Utamanya kepada Rektor UKDC Dr. Yustinus Budi Hermanto, M.M. yang senantiasa mendorong para dosen untuk membuat penelitian. Juga kepada Kepala LPPM UKDC Victor Imanuel Nalle, S.H., M.H. yang sedang menggalakkan penelitian, dan kepada (mantan) ketua LPPM UKDC Drs. Wahyu Krisnanto, M.A. yang membuka kesempatan bagi kami untuk mengunjungi Jember

Juga kepada Dekan Fakultas Teknik Lusi Mei Cahya Wulandari, S.T. M.T. dan Kepala Progdi Hukum Dyan Ety Mayasari, S.H., M.Hum. yang banyak memberi bantuan dan advis dalam proses pengerjaan penelitian ini.

\section{Daftar Pustaka}

Adisasmita, R. (2010). Pembangunan kawasan dan tata ruang, Yogyakarta: Graha Ilmu.

Ashcroft, B.; Griffiths, G. and Tiffin, H. (1998). Postcolonial studies, key concepts. London \& New York: Routledge.

Ching, F. D. K. (2012). Kamus visual arsitektur (alih bahasa: Aswin Indraprastha). Jakarta: Penerbit Erlangga.

Crowe, N. (1997). Nature and the idea of a man-made world. Cambridge, Massachussetts: The MIT Press.

Dehaene, M. \& De Cautier, L. (ed.) (2008). Heterotopian and the city: Public space in a postcivil society. London \& New York: Routledge.

Frick, H. (1997). Pola struktural dan teknik bangunan di Indonesia. Yogyakarta: Kanisius.

Fyfe, N.R. (ed.) (1998). Images of the street: Planning, identity and control in public space. London $\&$ New York: Routledge.

Handinoto (2010). Arsitektur dan kotakota di Jawa pada masa kolonial. Yogyakarta: Graha Ilmu.

Hariyono, P. (2007). Sosiologi kota untuk arsitek. Jakarta: Bumi Aksara.

Hernandez, F.; Millington, M. and Borden, I. (eds) (2005). Transculturation: Cities, spaces and architectures in Latin America. Amsterdam \& New York: Radopi.

Kusno, A. (2006). Di balik pascakolonial (alih bahasa: Titien Saraswati). Surabaya: Airlangga University Press. 
Laksono, E. (2013). Metropolis universalis. Jakarta: Elex Media Komputindo.

Mangunwijaya, Y.B. (2013). Wastu citra. Jakarta: PT. Gramedia Pustaka Utama.

Moleong, L. J. (2004). Metode penelitian kualitatif. Bandung: Remaja Rosda Karya.

Pontoh, N. K. \& Kustiwan, I. (2009). Pengantar perencanaan perkotaan. Bandung: Penerbit ITB.

Prihastoto (2003). Kajian kualitas ruang publik pada Alun-alun Kota Purworejo. (Tesis Program Pascasarjana Undip, Semarang, 2003. Tidak dipublikasikan).

Purnomo, A. B. (2009). Teknik kuantitatif untuk arsitektur dan perancangan kota. Jakarta: PT. Rajawali Press.

Surakhmad, W. (1994). Pengantar penelitian ilmiah. Bandung: Tarsito.

Utami, W.; Ginting, S. dan Eddy, F. (2004). Kajian stimulus collective memory terhadap bangunan-bangunan kolonial di sekitar Lapangan Merdeka Medan. Medan: USU. 